\title{
Effectiveness of seasonal influenza vaccine in preventing influenza primary care visits and hospitalisation in Auckland, New Zealand in 2015: interim estimates
}

\author{
A Bissielo ${ }^{1}$, N Pierse ${ }^{2}$, Q Huang ${ }^{1}$, M Thompson ${ }^{3}$, H Kelly ${ }^{4}$, V Mishin ${ }^{3}$, N Turner ${ }^{5}$, SHIVERS ${ }^{6}$ \\ 1. Institute of Environmental Science and Research, Wellington, New Zealand \\ 2. University of Otago, Wellington, New Zealand \\ 3. Influenza Division, Centers for Disease Control and Prevention, Atlanta, United States \\ 4. Victorian Infectious Diseases Reference Laboratory, Melbourne, Australia \\ 5. University of Auckland, Auckland, New Zealand \\ 6. Members of the 'SHIVERS' team are listed at the end of the article
}

Correspondence: N Turner (n.turner@auckland.ac.nz)

Citation style for this article:

Bissielo A, Pierse N, Huang Q, Thompson M, Kelly H, Mishin V, Turner N, SHIVERS. Effectiveness of seasonal influenza vaccine in preventing influenza primary care visits and hospitalisation in Auckland, New Zealand in 2015: interim estimates. Euro Surveill. 2016;21(1):pii=30101. D0I: http://dx.doi.org/10.2807/1560-7917.

ES.2016.21.1.30101

Preliminary results for influenza vaccine effectiveness (VE) against acute respiratory illness with circulating laboratory-confirmed influenza viruses in New Zealand from 27 April to 26 September 2015 , using a case testnegative design were $36 \%$ ( $95 \%$ confidence interval (CI): 11-54) for general practice encounters and 50\% (95\% Cl: 20-68) for hospitalisations. VE against hospitalised influenza $\mathrm{A}\left(\mathrm{H}_{3} \mathrm{~N}_{2}\right)$ illnesses was moderate at $53 \%$ (95\% Cl: 6-76) but improved compared with previous seasons.

\section{Introduction}

Seasonal influenza vaccines are used widely to reduce the burden of influenza, but effectiveness measures vary by a range of factors including season, age and underlying co-morbidities $[1,2]$. The Southern Hemisphere Influenza and Vaccine Effectiveness, Research and Surveillance (SHIVERS) study [3], running since 2012, allows estimation of vaccine effectiveness (VE) against patients presenting with influenza illness to general practice (primary care) and against influenza requiring hospitalisation. Reports were published for 2012, 2013 and 2014 [4-6]. Here we report the preliminary VE results for the 2015 influenza season in New Zealand.

\section{Methods}

We used the case test-negative design, as previously described [4], to estimate VE of southern hemisphere trivalent inactivated influenza vaccine (IIV 3 ) against laboratory-confirmed influenza in patients presenting during the 2015 winter season. We included patients who had presented to selected general practices with an influenza-like illness (ILI) or who had been hospitalised with a severe acute respiratory infection (SARI).
Both syndromes were defined as onset of an acute illness with a cough and a history of fever or measured temperature $\geq 38^{\circ} \mathrm{C}$; illnesses with onset within the past seven days before presentation were included in this report.

Ethics approval was obtained from the Northern A Health and Disability Ethics Committee (11/11/102/ AM02). The analysis was done on data collected between 27 April and 26 September 2015. The study population for both ILI and SARI came from the Central, South and East Auckland city districts with a population of ca 900,000.

ILI patients were recruited from 16 sentinel general practices that serve ca 100,000 enrolled patients. All identified ILI patients were screened for influenza by a general practitioner or practice nurse, and data were entered through an electronic form into the practice management system. SARI patients were recruited by a research nurse screening all patients admitted overnight with a respiratory illness, and data were collected on a case report form and completed with information from electronic hospital records. All consenting patients had a nasopharyngeal or throat swab collected for influenza virus testing.

Confirmed cases of influenza were defined as those with a positive laboratory result for any influenza virus detected by real-time reverse transcription PCR (rRT$P(R)$. As per previous years, all swabs were tested using the United States Centers for Disease Control and Prevention (CDC) protocol [7] or the AusDiagnostic $P C R$ protocol [8]. The assays detected influenza virus types A and B, A subtypes and B lineages. A screening 


\section{FIGURE 1}

Study participants with influenza-like illness $(n=1,197)$ and severe acute respiratory infection $(\mathrm{n}=754)$ who were influenza virus-positive or -negative, by week, Auckland, New Zealand, 27 April-26 September 2015

A. Influenza-like illness $(n=1,197)$

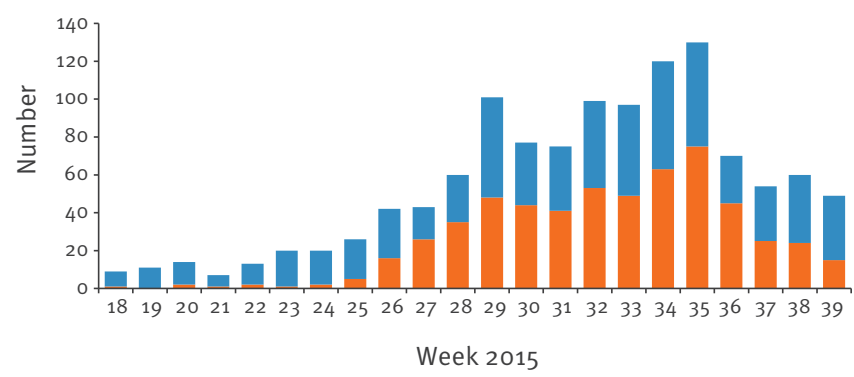

B. Severe acute respiratory infections $(n=754)$

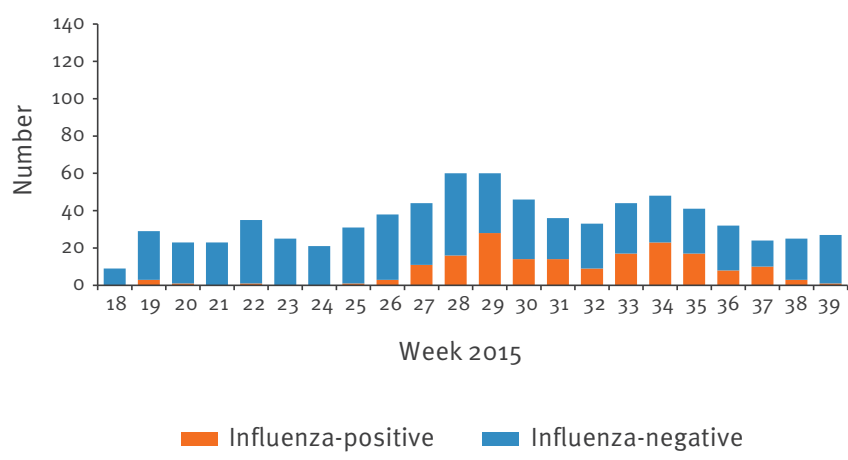

of $\mathrm{A}\left(\mathrm{H}_{3} \mathrm{~N}_{2}\right)$ viruses for genetic markers associated with six major haemagglutinin ( $\mathrm{HA})$ genetic groups ( $3 \mathrm{C} .2$, $3 \mathrm{C} .2 \mathrm{a}, 3 \mathrm{C} .2 \mathrm{~b}, 3 \mathrm{C} .3,3 \mathrm{C} .3 \mathrm{a}$, and $3 \mathrm{C} .3 \mathrm{~b}$ ) was done with a pyrosequencing assay. The detailed protocol for the $\mathrm{H}_{3}$ genetic groups pyrosequencing assay is available upon request (fluantiviral@cdc.gov).

Vaccination status for ILI patients was ascertained from electronic documentation in the general practice records. For SARI patients, vaccination status was based on self-report. A patient was considered fully vaccinated if they had received at least one selfreported or documented dose of the 2015 influenza vaccine.

We excluded infants younger than six months, those vaccinated less than 14 days before illness onset and those with symptom onset more than seven days before presentation. For patients with multiple illness presentations, the first influenza virus-positive episode was used for the analysis or, when there was no influenza virus-positive episode, the first illness episode.

VE was analysed for all influenza viruses, subtypes and clades. Unconditional logistic regression was used to compare the odds of vaccination among influenza virus-positive vs influenza virus-negative participants for both ILI and SARI datasets, with VE estimated as $100 \% \times(1-O R)$. VE estimates were adjusted for age

\section{FIGURE 2}

Flowchart of all patients with influenza-like illness $(n=1,197)$ and severe acute respiratory infection $(n=754)$ selected, recruited and tested for influenza vaccine effectiveness analysis, Auckland, New Zealand, 27 April-26 September 2015

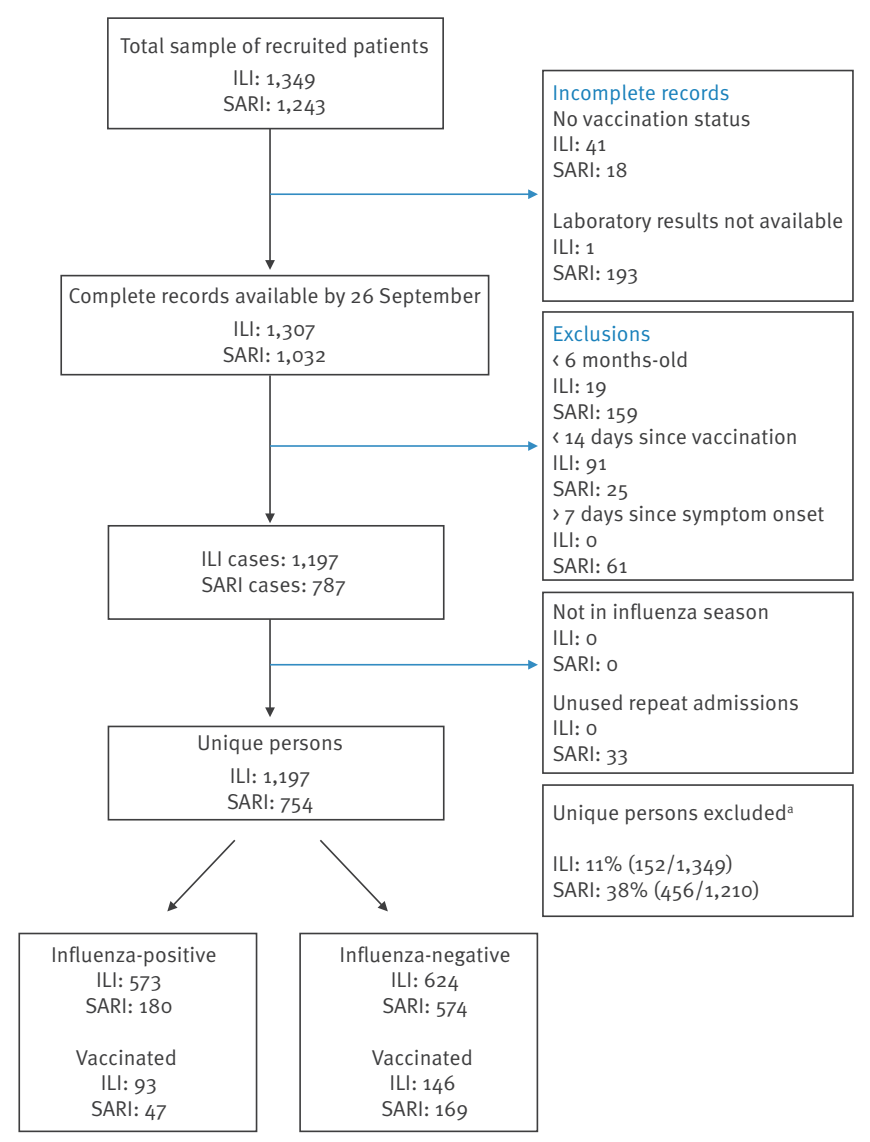

ILI: Influenza-like illness; SARI: severe acute respiratory infection.

a A number of SARI patients are admitted to hospital multiple times. The total of 1,243 included multiple admissions, which were removed in this box.

group, calendar week, any underlying health condition and days since illness onset at swab collection.

\section{Results}

In total, 1,197 ILI and 754 SARI patients were included for analysis (Figure 1 and Figure 2).

Of these, 573 (47.9\%) of the ILI and 180 (23.9\%) of the SARI were influenza virus-positive (Figure 2). Of all influenza infections, 399 were with influenza A viruses (285 ILI and $114 \mathrm{SARI}) ; 281$ were influenza $A\left(\mathrm{H}_{3} \mathrm{~N}_{2}\right)$, one was $A / C a l i f o r n i a / 7 / 2009\left(\mathrm{H}_{1} \mathrm{~N}_{1}\right)$ and 117 were not subtyped at the time of reporting. All 101 pyrosequenced influenza $A\left(\mathrm{H}_{3} \mathrm{~N}_{2}\right)$ samples were identified as clade $3 \mathrm{C} .2 \mathrm{a}$ (86 ILI and $15 \mathrm{SARI}$ ), which is like the vaccine component. There were 354 influenza B viruses (288 ILI and 66 SARI); 140 were B/Yamagata (including 95 $\mathrm{B} /$ Phuket/3073/2013 lineage), 159 were $\mathrm{B} /$ Victoria (including $52 \mathrm{~B} /$ Brisbane/60/2008 lineage) and 55 were not genotyped at the time of reporting. 
Crude and adjusted estimated influenza vaccine effectiveness by age group and influenza virus type and subtype, Auckland, New Zealand, 27 April-26 September 2015

\begin{tabular}{|c|c|c|c|c|c|c|c|c|c|c|}
\hline \multirow{2}{*}{$\begin{array}{l}\text { Influenza type } \\
\text { or } \\
\text { Age groups }\end{array}$} & \multicolumn{3}{|c|}{ Influenza-positive } & \multicolumn{3}{|c|}{ Influenza-negative } & \multicolumn{2}{|c|}{ Unadjusted } & \multicolumn{2}{|c|}{ Adjusted $^{\mathrm{a}}$} \\
\hline & $\begin{array}{c}\text { Number } \\
\text { vaccinated }\end{array}$ & Total & $\%$ & $\begin{array}{c}\text { Number } \\
\text { vaccinated }\end{array}$ & Total & $\%$ & VE \% & $95 \% \mathrm{Cl}$ & VE \% & $95 \% \mathrm{Cl}$ \\
\hline \multicolumn{11}{|l|}{ ILI } \\
\hline Overall & 93 & 573 & 16 & 146 & 624 & 23 & 37 & 15 to 52 & 36 & 11 to 54 \\
\hline 6 months -17 years & 15 & 260 & 6 & 26 & 258 & 10 & 45 & -6 to 72 & 50 & 1 to 75 \\
\hline 18-64 years & 59 & 287 & 21 & 89 & 331 & 27 & 30 & -2 to 52 & 27 & -8 to 51 \\
\hline$\geq 65$ years & 19 & 26 & 73 & 31 & 35 & 89 & 65 & -36 to 91 & 67 & -41 to 92 \\
\hline Influenza A & 54 & 285 & 19 & 146 & 624 & 23 & 23 & -9 to 46 & 24 & -15 to 50 \\
\hline $\mathrm{A}\left(\mathrm{H}_{3} \mathrm{~N}_{2}\right)$ & 45 & 216 & 21 & 146 & 624 & 23 & 14 & -26 to 41 & 22 & -23 to 51 \\
\hline Influenza B & 39 & 288 & 14 & 146 & 624 & 23 & 49 & 25 to 65 & 46 & 17 to 65 \\
\hline B/Yamagata & 18 & 131 & 14 & 146 & 624 & 23 & 48 & 11 to 69 & 35 & -18 to 64 \\
\hline B/Victoria & 19 & 145 & 13 & 146 & 624 & 23 & 56 & 22 to 75 & 56 & 22 to 75 \\
\hline \multicolumn{11}{|l|}{ SARI } \\
\hline Overall & 47 & 180 & 26 & 169 & 574 & 29 & 15 & -24 to 42 & 50 & 20 to 68 \\
\hline 6 months -17 years & 3 & 55 & 5 & 30 & 312 & 10 & NA & NA & NA & NA \\
\hline $18-64$ years & 25 & 92 & 27 & 61 & 154 & 40 & 43 & o to 68 & 46 & 1 to 70 \\
\hline$\geq 65$ years & 19 & 33 & 58 & 78 & 108 & 72 & 48 & -17 to 77 & 52 & -14 to 79 \\
\hline Influenza A & 33 & 114 & 29 & 169 & 574 & 29 & 2 & -52 to 37 & 54 & 21 to 73 \\
\hline $\mathrm{A}\left(\mathrm{H}_{3} \mathrm{~N}_{2}\right)$ & 19 & 65 & 29 & 169 & 574 & 29 & 1 & -74 to 44 & 53 & 6 to 76 \\
\hline Influenza B & 14 & 65 & 22 & 169 & 574 & 29 & 34 & -22 to 65 & 40 & -24 to 71 \\
\hline
\end{tabular}

$\mathrm{CI}$ : Confidence interval; ILI: Influenza-like illness; NA: not applicable; SARI: severe acute respiratory infections; VE: vaccine effectiveness. Overall: includes any influenza and all ages $\geq 6$ months; B/Yamagata: B/Yamagata lineage + B/Phuket/3073/2013-like; B/Victoria: B/Victoria lineage + B/Brisbane $/ 60 / 2008$-like.

${ }^{a}$ Adjusted for six age groups $(<6,6-17,18-45,46-64,65-79$ and $\geq 80$ years), week in season, any underlying health condition and days since illness onset at swab collection.

Data source: SHIVERS 27 April to 26 September 2015 (week 18-week 39).

Among ILI patients of all ages, 93 of $573(16 \%)$ influenza virus-positive persons and 146 of 624 (23\%) influenza virus-negative persons were vaccinated, resulting in a crude VE against all circulating influenza strains of $37 \%$ (95\% confidence interval $(\mathrm{Cl}): 15-52$ ); VE adjusted for variables listed in the methodology was 36\% (95\% $\mathrm{Cl}: 11-54)$. Adjusted VE point estimates by age group were $50 \%, 27 \%$ and $67 \%$ for patients aged 6 months to 17 years, $18-64$ years and $\geq 65$ years, respectively, but with wide confidence intervals (Table).

For all ages, the adjusted VE against ILI with influenza $\mathrm{A}\left(\mathrm{H}_{3} \mathrm{~N}_{2}\right)$ viruses was $22 \%(95 \% \mathrm{Cl}:-23$ to 51$)$, but the VE point estimate, though not statistically significant, was slightly higher for the subset identified as Clade 3C.2a: $27 \%$ (95\% Cl: -46 to 63 ). For all ages, the adjusted VE against ILI with any influenza $B$ virus was $46 \%$ (95\% Cl: 17-65), but the VE point estimate, though not statistically significant, was slightly higher for the B/Victoria than for B/Yamagata lineage.

Among hospitalised SARI patients of all ages, 47 of 180 (26\%) influenza-positive persons and 169 of 574 (29\%) influenza-negative persons were vaccinated, resulting in a crude VE of $15 \%(95 \% \mathrm{Cl}:-24$ to 42$)$ against circulating influenza viruses. VE adjusted for age, week, underlying conditions and days since onset was higher at 50\% (95\% Cl: 20-68). Adjusted VE point estimates against SARI influenza by age were $49 \%, 46 \%$ and $52 \%$ for patients aged 6 months to 17 years, $18-64$ years and $\geq 65$ years, respectively, but with wide confidence intervals (Table) ( $p$ interaction $=0.99$ ). Age-adjusted VE for influenza $A\left(\mathrm{H}_{3} \mathrm{~N}_{2}\right)$ virus-associated SARI was $53 \%$ (95\% Cl: 6-76); we did not have a sufficient number of Clade 3 C.2a identified viruses to date to do a cladespecific SARI VE estimate. Finally, for SARI associated with influenza B (of either lineage), adjusted VE was $40 \%(95 \% \mathrm{Cl}:-24$ to 71$)$.

\section{Background}

In New Zealand, the influenza season occurs between March and September, and southern hemisphere $\mathrm{IIV}_{3}$ is offered annually free of charge from early March to all those older than six months with high risk medical conditions, to pregnant women and to those 65 years and older. The influenza strains in the 2015 trivalent vaccine were $A / C a l i f o r n i a / 7 / 2009\left(\mathrm{H}_{1} \mathrm{~N}_{1}\right)$-like virus, A/Switzerland/9715293/2013 ( $\left.\mathrm{H}_{3} \mathrm{~N}_{2}\right)$-like virus and B/ Phuket/3073/2013-like virus. 


\section{Discussion}

The 2015 New Zealand influenza season was dominated by influenza $A\left(\mathrm{H}_{3} \mathrm{~N}_{2}\right)$ and $B$ viruses (including both $\mathrm{B} /$ Victoria and $\mathrm{B} /$ Yamagata lineages). Our interim results suggest that $I I V_{3}$ was ca $37-50 \%$ effective at preventing influenza-associated acute respiratory illnesses (with fever and cough) that resulted in general practice visits or hospitalisation. If this trend continues, the overall VE observed in 2015 will be similar to the moderate VE reported during the previous three influenza seasons in New Zealand, even though the virus mix was different. VE point estimates have been consistently around 50\% with minimal differences between ambulatory and inpatient medical care [4-6].

In 2014, although influenza $A\left(\mathrm{H}_{1} \mathrm{~N}_{1}\right)$ pdmog was the predominant circulating strain, $A\left(\mathrm{H}_{3} \mathrm{~N}_{2}\right)$ viruses were also in circulation. During 2014, we observed no measureable protection of southern hemisphere $\mathrm{IIV}_{3}$ against influenza $\mathrm{A}\left(\mathrm{H}_{3} \mathrm{~N}_{2}\right)$ virus-associated ILI or SARI [9]. This was consistent with reports from the northern hemisphere during the $2014 / 15$ season, when the $A /$ Texas/50/2012 ( $\left.\mathrm{H}_{3} \mathrm{~N}_{2}\right)$-like component of the vaccine was not a good match to the circulating strains [1013]. The influenza $A\left(\mathrm{H}_{3} \mathrm{~N}_{2}\right) I_{3} \mathrm{IV}_{3}$ component was subsequently changed to $A / S w i t z e r l a n d / 9715293 / 2013$ $\left(\mathrm{H}_{3} \mathrm{~N}_{2}\right)$-like virus. In this interim 2015 report, all influenza $A\left(\mathrm{H}_{3} \mathrm{~N}_{2}\right)$ viruses with pyrosequencing performed to date belonged to the genetic clade $3 \mathrm{C} .2 \mathrm{a}$, which is antigenically related to the vaccine clade 3 C.3a.

We are encouraged by our interim observation of positive VE point estimates for influenza $\mathrm{A}\left(\mathrm{H}_{3} \mathrm{~N}_{2}\right)$ virusassociated ILI (22\%; $95 \% \mathrm{Cl}:-23$ to 51$)$ and SARI (53\%; $95 \% \mathrm{Cl}: 6-76)$, which may indicate that VE improved with the change in vaccine strain.

The precision of our interim estimates was limited by relatively small numbers of observations for some ages and outcomes. Large differences in vaccination uptake and influenza positivity between age groups also resulted in substantial differences between our crude and adjusted VE estimates for SARI. Specifically, when we combined the data across ages, the lower vaccination coverage among children and greater likelihood of older age groups testing positive for influenza virus biased the crude VE estimate towards the null (i.e. Simpson's paradox which occurs because vaccination and the likelihood of testing positive are both correlated with age [14]).

Our interim results are subject to at least four other limitations. Firstly, the hospitalised patient results are based on self-reported vaccination status. However self-reporting has been shown to be generally accurate, especially among hospitalised elderly patients [15], and when comparing self-reporting with documented vaccination status, VE estimates have been shown to be very similar [16]. Secondly, the precision of our age and (sub)type-specific estimates was low given the use of preliminary data with few observations in many categories. Thirdly, we adjusted for covariates included in prior VE analyses, but a complete examination of potential confounders, including confirmation of chronic medical conditions must await our final report. Finally, we examined VE for a single dose only and because of pending vaccination records and small numbers of children enrolled to date we could not examine VE for the two-dose regimen recommended for children under the age of nine years.

Similar to previous SHIVERS studies, this study suggests that inactivated influenza vaccines provided moderate protection against laboratory-confirmed influenza virus illness in general practice and hospital settings.

Southern Hemisphere Influenza Vaccine Effectiveness, Research and Surveillance (SHIVERS) investigation team (listed in an alphabetical order)

Bruce Adlam, Michael Baker, Don Bandaranayake, Judy Bocacao, John Cameron, Kirstin Davey, Gillian Davies, Jazmin Duque, Leane Els, Cameron C. Grant, Rosemary Gordon, Diane Gross, Wendy Gunn, Kathryn Haven, Marion Howie, Lauren Jelly, Shirley Lawrence, Graham Mackereth, Barbara McArdle, Colin McArthur, Claire Newbern, Namrata Prasad, Thomas Metz, Fahimeh Rahnama, Jacqui Ralston, Gary Reynolds, Sally Roberts, Sarah Radke, Ruth Seeds, Susan Taylor, Paul Thomas, Adrian Trenholme, Angela Todd, Ben Waite, Richard Webby, Deborah A. Williamson, Marc-Alain Widdowson, Conroy Wong, Tim Wood, Larisa Gubareva.

\section{Acknowledgements}

The SHIVERS (Southern Hemisphere Influenza and Vaccine Effectiveness Research and Surveillance) project is funded by the United States Department of Health and Human Services, Centers for Disease Control and Prevention (CDC) (1U01lPoo0480).

The SHIVERS project is a multiagency and multidisciplinary collaboration: Institute of Environmental Science and Research, Auckland District Health Board, Counties Manukau District Health Board, University of Auckland, University of Otago, the US Centres for Disease Control and Prevention and WHO Collaborating Centre at St Jude Children's Research Hospital in Memphis, United States.

WHO Collaborating Centre for Research and Surveillance of Influenza, Melbourne and US Centres for Disease Control and Prevention for supplying antigenic typing reagents and some results for influenza isolates.

The 16 participating sentinel general practices from Auckland PHO, East Tamaki Health Care and ProCare.

The findings and conclusions in this report are those of the authors and do not necessarily represent the views of the US Centers for Disease Control and Prevention.

\section{Conflict of interest}

None declared. 


\section{Authors' contributions}

Ange Bissielo: involved in study design, data collection and analysis, interpretation and manuscript development. Nevil Pierse: involved in study design, methodological design, data analysis, interpretation and manuscript development. Q Sue Huang: principal investigator for the larger SHIVERS study, involved in study design, implementation, and manuscript development. Mark Thompson: involved in study design, interpretation and manuscript development. Heath Kelly: involved in study design, methodological analysis, data analysis and interpretation, manuscript development and editing. Vasiliy Mishin: involved in methodological and data analysis analysis, Nikki Turner: involved in study design, implementation, analysis, manuscript development.

\section{References}

1. Manzoli L, Ioannidis JP, Flacco ME, De Vito C, Villari P. Effectiveness and harms of seasonal and pandemic influenza vaccines in children, adults and elderly: a critical review and re-analysis of 15 meta-analyses. Hum Vaccin Immunother. 2012;8(7):851-62. DOI: 10.4161/hv.19917 PMID: 22777099

2. Osterholm MT, Kelley NS, Sommer A, Belongia EA. Efficacy and effectiveness of influenza vaccines: a systematic review and meta-analysis.Lancet Infect Dis. 2012;12(1):36-44. DOI: 10.1016/S1473-3099(11)70295-X PMID: 22032844

3. Huang QS, Baker M, McArthur C, Roberts S, Williamson D, Grant $C$, et al. Implementing hospital-based surveillance for severe acute respiratory infections caused by influenza and other respiratory pathogens in New Zealand. Western Pac Surveill Response J. 2014;5(2):23-30. DOI: 10.5365/ wpsar.2014.5.1.004 PMID: 25077034

4. SHIVERS investigation team,Turner N, Pierse N, Bissielo A, Huang Q, Radke S, Baker M, et al. . Effectiveness of seasonal trivalent inactivated influenza vaccine in preventing influenza hospitalisations and primary care visits in Auckland, New Zealand, in 2013.Euro Surveill. 2014;19(34):pii: 20884 DOI: 10.2807/1560-7917.ES2014.19.34.20884 PMID: 25188614

5. SHIVERS investigation team,Turner N, Pierse N, Huang QS, Radke S, Bissielo A, Thompson MG, et al. . Interim estimates of the effectiveness of seasonal trivalent inactivated influenza vaccine in preventing influenza hospitalisations and primary care visits in Auckland, New Zealand, in 2014. Euro Surveill. 2014;19(42):20934. DOI: 10.2807/1560-7917. ES2014.19.42.20934 PMID: 25358042

6. SHIVERS investigation team,Turner N, Pierse N, Bissielo A, Huang QS, Baker MG, Widdowson M-A, et al. . The effectiveness of seasonal trivalent inactivated influenza vaccine in preventing laboratory confirmed influenza hospitalisations in Auckland, New Zealand in 2012.Vaccine. 2014;32(29):3687-93. DOI: 10.1016/j.vaccine.2014.04.013 PMID: 24768730

7. Shu B, Wu KH, Emery S, Villanueva J, Johnson R, Guthrie $E$, et al. Design and performance of the CDC real-time reverse transcriptase PCR swine flu panel for detection of $2009 \mathrm{~A}\left(\mathrm{H}_{1} \mathrm{~N}_{1}\right)$ pandemic influenza virus. I Clin Microbiol. 2011;49(7):2614-9. DOI: 10.1128/JCM.02636-10 PMID: 21593260

8. Szewczuk E, Thapa K, Anninos T, McPhie K, Higgins G, Dwyer $\mathrm{DE}$, et al. Rapid semi-automated quantitative multiplex tandem PCR (MT-PCR) assays for the differential diagnosis of influenzalike illness. BMC Infect Dis. 2010;10(1):113. DOI: 10.1186/14712334-10-113 PMID: 20459845

9. Pierse N, Kelly H, Thompson M, Bissielo A, Radke S, Huang $\mathrm{QS}$, et al. Influenza vaccine effectiveness for hospital and community patients using control groups with and without non-influenza respiratory viruses detected. Vaccine. Forthcoming.

10. Pebody RG, Warburton F, Ellis J, Andrews N, Thompson C, von Wissmann B, et al. Low effectiveness of seasonal influenza vaccine in preventing laboratory-confirmed influenza in primary care in the United Kingdom: 2014/15 mid-season results. Euro Surveill. 2015;20(5):21025. DOI: 10.2807/15607917.ES2015.20.5.21025 PMID: 25677050

11. Pediatric Acute Lung Injury and Sepsis Investigators (PALISI) Network, Ferdinands JM, Olsho LE, Agan AA, Bhat N, Sullivan RM, Hall $M$, et al. . Effectiveness of influenza vaccine against life-threatening RT-PCR-confirmed influenza illness in US children, 2010-2012.J Infect Dis. 2014;210(5):674-83. DOI: 10.1093/infdis/jiu185 PMID: 24676207

12. Investigators of the Serious Outcomes Surveillance Network of the Canadian Immunization Research Network (CIRN), McNeil SA, Andrew MK, Ye L, Haguinet F, Hatchette
TF, ElSherif M, et al. . Interim estimates of 2014/15 influenza vaccine effectiveness in preventing laboratory-confirmed influenza-related hospitalisation from the Serious Outcomes Surveillance Network of the Canadian Immunization Research Network, January 2015.Euro Surveill. 2015;20(5):21024. DOI: 10.2807/1560-7917.ES2015.20.5.21024 PMID: 25677052

13. Centers for Disease Control and Prevention,Flannery B, Clippard J, Zimmerman RK, Nowalk MP, Jackson ML, Jackson LA, et al. . Early estimates of seasonal influenza vaccine effectiveness - United States, January 2015.MMWR Morb Mortal Wkly Rep. 2015;64(1):10-5.PMID: 25590680

14. Wagner CH. Simpson's paradox in real life.Am Stat. 1982;36(1):46-8. DOI: 10.1080/00031305.1982.10482778

15. Skull SA, Andrews RM, Byrnes GB, Kelly HA, Nolan TM, Brown GV, et al. Validity of self-reported influenza and pneumococcal vaccination status among a cohort of hospitalized elderly inpatients. Vaccine. 2007;25(25):4775-83. DOI: 10.1016/j. vaccine.2007.04.015 PMID: 17499402

16. Ohmit SE, Thompson MG, Petrie JG, Thaker SN, Jackson ML, Belongia EA, et al. Influenza vaccine effectiveness in the 2011-2012 season: protection against each circulating virus and the effect of prior vaccination on estimates. Clin Infect Dis. 2014;58(3):319-27. DOI: 10.1093/cid/cit736 PMID: 24235265

\section{License and copyright}

This is an open-access article distributed under the terms of the Creative Commons Attribution (CC BY 4.0) Licence. You may share and adapt the material, but must give appropriate credit to the source, provide a link to the licence, and indicate if changes were made.

This article is copyright of the authors, 2016. 